\title{
A TRANSFORMAÇÃO DO TERRITÓRIO A PARTIR DO USO DA TERRA NO MUNICÍPIO DE SANTARÉM PARÁ
}

\author{
Barbara Eleonora Santos Teixeira ${ }^{1}$ \\ Thiago Silva dos Santos ${ }^{2}$ \\ Ademir Terra ${ }^{3}$
}

\begin{abstract}
RESUMO
Este artigo foi construído no intuito de analisar os impactos do agronegócio da soja no município de Santarém no Oeste do Pará, e como a chegada dessa lógica na região acarretou mudanças no uso e ocupação da terra, requalificando antigas formas e funções espaciais. Os dados da pesquisa apontam para um caráter de substituição de algumas culturas anuais pela monocultura da soja e a introdução desses novos agentes de produção no território acabam por desencadear conflitos pelo uso e apropriação da terra; os diversos sujeitos territoriais presentes neste território divergem em interesses econômicos e sociais.
\end{abstract}

Palavras-chave: Agronegócio. Soja. Território. Santarém.

\begin{abstract}
This article was built to analyze the impacts of soy agribusiness in the municipality of Santarem in western Pará. With the arrival of this logic in the region brought about changes in land use and occupation, requalifying ancient forms and spatial functions. The research data point to the substitution of some annual crops by soy monoculture and the introduction of these new production agents in the territory end up triggering conflicts over land use and appropriation. the various territorial subjects present in this territory differ in economic and social interests.
\end{abstract}

Keywords: Agribusiness. Soy. Territory. Santarem.

\section{INTRODUÇÃO}

O território amazônico historicamente sofre com pressões, as quais foram intensificadas a partir das décadas de 1950 e 1970 de maneira espontânea e/ou direcionada, a partir da abertura de suas fronteiras,condicionada pelas migrações e pelas construções de eixos rodoviários, aumentando a porosidade deste território. Neste período, inaugura-se um tempo onde o Estado brasileiro implantou diversas ações, objetivando o domínio do território para o uso da terra e, por conseguinte, à reprodução ampliada do modo capitalista de produção. No corpo dessas ações destaca-se a introdução efetiva e articulada dos sistemas de decisões e das estruturas tributárias da decisão, sendo manifestadas em sistemas de ações e objetos (SANTOS, 2014).

Nesse contexto, colonos provenientes, sobretudo, do Nordeste e do Centro-Sul do país migram para a região de Santarém, passando a desenvolver atividades ligadas ao extrativismo e a agricultura de subsistência, de forma arcaica, utilizando apenas a força de trabalho como mecanismo e sem contar com incentivos do governo. Mas no fim da década de 1990, esse cenário sofre alterações com a inserção de grandes plantios de soja nesse território, por meio de produtores vindos do Centro-Sul do país, atraídos pela disponibilidade de terra a baixo custo, e mais ainda, essa região possui acesso privilegiado aos mercados internacionais. Soma-se a esses fatores os vários incentivos do Estado, que passa a ver no agronegócio uma estratégia de elevar a economia nacional.

Estão dadas as condições do avanço do agronegócio da soja, precisamente no município de Santarém que se intensificou com a implantação do porto graneleiro da multinacional Cargill

\footnotetext{
${ }^{1}$ Doutoranda do Programa de Pós-Graduação em Geografia - Universidade Federal do Pará (IFCH/UFPA). E-mail: barbara.teixeira.ufpa@gmail.com

${ }^{2}$ Mestrando do Programa de Pós-Graduação em Geografia - Universidade Federal do Pará (IFCH/UFPA). E-mail: thiagogeografiaatm@gmail.com

${ }^{3}$ Professor do Departamento de História e Geografia (DHG) da Universidade Estadual do Maranhão (UEMA). Email: ademirterra@professor.uema.br
} 
no ano de 2003. Desde então, o município vem apresentando mudanças no uso da terra. O estudo e discussão destes fenômenos nos ajudam a compreender como ocorre a organização e ordenamento do território na Amazônia, sobretudo, a partir dos incentivos do Estado para o avanço do agronegócio nesta região.

Pautado nisso, buscamos analisar a influência do agronegócio da soja nas mudanças do uso da terra no município Santarém, pois, a chegada dessa nova frente produtiva traz consigo uma lógica ligada à agricultura moderna, utilizando tecnologia e trabalho mecanizado com capacidade de rápida transformação da realidade local, capaz de provocar alterações na dinâmica produtiva existente, que em um curto período de tempo, surge a necessidade da compreensão desse território frente o avanço das relações de produção capitalista.

Para o desenvolvimento deste trabalho, utiliza-se o método dialético, pois a compreensão dos processos de ordem global é fundamental para a interpretação das contradições estabelecidas no território, tal como se apresenta a quarta lei da dialética (transformação da quantidade em qualidade). Por conseguinte, entender a dinâmica presente nesta porção do território amazônico é fundamental para a compreensão do todo com as partes, propiciando uma interpretação das mudanças ocorridas no território até os dias atuais.

Partindo disto, há condições metodológicas para aprofundar na genética do problema, entre uma abordagem subjetiva do fenômeno da monocultura da soja e produtos obtidos através dos dados espaciais, junto com tabelas dialogando com a problemática, além de uma outra ferramenta importante nos estudos geográficos, que servem fundamentalmente aos estudos territoriais, os Sistemas de Informações Geográficas (SIG), que no contexto em estudo servirá para localizar, espacializar e definir situações e problemas espaciais ligados ao uso e ocupação da terra no município de Santarém.

Para a espacialização e localização do problema em questão, utilizou-se de dados do IBGE, Google Earth e MapBiomas por meio da interface Google Earth Engine, para tratamento e produção das cartografias necessárias ao estudo. Geramos assim, cartografias de uso e ocupação da terra do município de Santarém nos anos de 2000 e 2017.

Entendendo que o foco da pesquisa é compreender os principais fatores de mudança do uso da terra a partir do avanço do agronegócio em Santarém, elegemos uma cartografia das classes cultura anual e perene, juntamente com a de mosaico de agricultura e pastagem, com o recorte nos anos de 2006 e 2017, período de maior pressão no padrão de uso da terra neste território, onde o primeiro é majoritariamente expresso pelo agronegócio da soja, juntamente com demais culturas de pequenos ciclos e de culturas perenes; o segundo compõe um campo diverso de culturas ligadas diretamente à agricultura camponesa, com culturas consorciadas com a pastagem.

Para o processamento dos dados e geração de cenários, foi utilizado o software livre QGIS 2.18.21. Assim, tratamos os dados de uso e ocupação disponíveis no banco de dados do MapBiomas dos anos 2000 e 2017. No processo, foram geradas as classes floresta, formação não florestal, pastagem, cultura anual e perene, mosaico de agricultura e pastagem, área não vegetada, urbano, hidrografia e área não observada,disponibilizadas para a referida área de estudos e orientadas pela tabela de legenda 3.1 do site base.

A partir desta metodologia, foi possível montar um recorte cartográfico de Santarém nos anos de 2000 e 2017 para balizar e dar sustentação à tese das mudanças no uso da terra no município, que nos permite observar as aludidas mudanças no perfil produtivo ligado à monocultura e à pecuária, principalmente. Tais alterações, evidenciam o caráter estratégico do movimento crescente do capital agroindustrial no território amazônico.

A primeira parte deste texto tem como enfoque a clarificação sobre a expansão capitalista na Amazônia e suas consequências sobre os sujeitos locais; em seguida, apresenta-se a metodologia abordada no trabalho para, por fim, apresentar os resultados e discussão.

\section{NOVAS RELAÇÕES DE PODER NO ESPAÇO RURAL SANTARENO}


Os sistemas de objetos e sistemas de ações implantados na Amazônia, a partir do avanço da fronteira de expansão do capital, cria novas condições de uso da terra. Esses novos usos, provocados pelo sistema capitalista, implicam nas transformações das relações dos sujeitos no território, requalificando antigas formas e funções espaciais, trazendo novas relações de poder para o território, a partir das políticas do Estado e do capital. A fixação dessas políticas tem o papel central de articular capital privado e Estado para a região, caracterizada como fronteira de recursos naturais. Assim, a Amazônia como território obedecerá à lógica dos interesses de agentes hegemônicos, que, a partir das demandas e estímulos mercadológicos, passam a fixar políticas ligadas ao grande capital agrícola, desconsiderando as práticas históricas existentes no território (BECKER, 2005).

Essa nova lógica projeta uma estrutura de fronteira baseada no discurso do grande capital, que constrói uma identidade modernizante e civilizatória para o campo, projetando-se sobre um coletivo discordante (SILVA, 2011). Assim, o avanço de uma nova fronteira capitalista/produtiva entoa uma dinâmica de acumulação no campo, revelando valores e práticas conflitantes, que nos passos da história vai transformando o território, e moldando-o de acordo com as demandas do mercado.

No município de Santarém, os vetores da modernização capitalista se territorializaram através da BR-163 (Cuiabá-Santarém) e dos incentivos à pecuária nas décadas de 1970 e 1980, que integra um sistema madeira-pecuária e mais recentemente, a soja. A produção desta soja na Amazônia se deve aos vários incentivos estatais, sobretudo, no Pará, ao garantir e expandir a monocultura no Estado com o objetivo de alavancar a economia. O município de Santarém, no Oeste do Pará, apresenta características físicas (relevo planáltico) que propicia a agricultura mecanizada, além de ser uma área estratégica, do ponto de vista da logística de escoamento de grãos, pela BR-163 até o porto da graneleiro da Cargill nas confluências dos rios Amazonas e Tapajós na cidade de Santarém.

Este processo de expansão da monocultura da soja em Santarém se torna mais intenso a partir do fomento oferecido pelo governo paraense através do Plano Plurianual (PPA) entre os anos 1996 e 1999 para a introdução da monocultura da soja no planalto santareno, como estratégia de crescimento econômico do Estado junto a economia internacional de commodities, tal como destaca Barros (2018):

\footnotetext{
Dentre as ações estratégicas para o setor da agropecuária traçadas por Pará (1995, p.68) constam o fomento ao cultivo de grãos sob a execução da Secretaria de Estado de Agricultura do Pará (SAGRI) e a implementação do programa agroindustrial da soja sob execução da Secretaria de Estado de Agricultura do Pará (SAGRI) da Empresa de Assistência Técnica do Pará (EMATER), da Secretaria de Estado da Indústria e Comércio do Pará (SEICON) do Banco do Estado do Pará (BANPARA) e da Secretaria de Estado da Fazenda do Pará (SEFA). (BARROS, 2018, p. 4).
}

Segundo o autor as ações estratégicas ficaram a cargo das secretarias ligadas ao setor agropecuário do Estado, assim como os incentivos financeiros a cargo do banco Estado do Pará. Desta forma, o Estado garantiu os estudos de correção e aproveitamento do solo, já que é notório que a região amazônica oferece pouquíssimas áreas de solo adequado a agricultura extensiva, necessitando haver estudos de adequação do solo a esta cultura. "Com as ações do Governo do 
Pará e da Prefeitura de Santarém o plantio de soja logo se concentrou ao longo das rodovias PA370 e BR-163 em Santarém" (BARROS, 2018).

Segundo Nahum e Paixão Júnior (2014), essas ações do Estado provocaram novas dinâmicas no uso da terra, que antes era usada na produção camponesa, através das famílias, que cultivavam pequenas extensões de terras para as práticas da agricultura rudimentar. No entanto, com a chegada de migrantes em busca de novas terras para o cultivo extensivo da soja, essas culturas passaram a dar lugar a uma única cultura que tinha como objetivo usar as áreas de degradação ambiental, sejam elas antigos campos da pecuária, savana, capoeira, ou até mesmo áreas já cultivadas por pequenos agricultores para a implementação de uma agricultura de commodities para exportação, desencadeando-se assim,

[...] intensa apropriação das terras do Planalto Santareno pelo agronegócio, seguida de
um acelerado processo de esvaziamento populacional das comunidades camponesas. Isso
porque as plantações de soja, para se tornarem rentáveis economicamente requerem
solos que já sofreram alguma ação do homem. Logo, as terras há tempos cultivadas pelos
camponeses serviriam convenientemente para o cultivo mecanizado. A isto associam-se
as dificuldades encontradas pelos camponeses para a sua reprodução, em razão da
precariedade da infraestrutura das comunidades, do baixo nível do consumo familiar e
do trabalho degradante do roçado. Os camponeses venderam seus lotes aos chamados
"gaúchos", mas que também eram goianos, mato-grossenses, paranaenses, tocantinenses,
a preços muito inferiores àqueles praticados nas regiões de onde vieram (NAHUM;
PAIXÃO JUNIOR, 20014, p. 49).

A intensidade da apropriação da terra destacada pelos autores acarreta uma mudança na forma de uso da terra, sobretudo na substituição da diversidade de culturas pela monocultura. No entanto, os autores chamam a atenção para outros fatores que ocasionam essas mudanças, como o esvaziamento de comunidades inteiras que passam a vender suas terras aos novos produtores de soja para tentarem a vida na cidade, ou o intenso uso de defensivos agrícolas, causando conflitos com os pequenos produtores que permaneceram na terra, sobretudo, motivado pela degradação dos recursos hídricos e condição de fertilidade do solo.

A introdução de novos agentes de produção pressupõe a existência de múltiplos poderes no território, desencadeando conflitos pelo uso e apropriação da terra, pois os diversos sujeitos territoriais possuem práticas e costumes divergentes os quais, na maioria das vezes, aos interesses sociais locais sobrepõem os interesses econômicos privados. As múltiplas relações de poder precisam ser consideradas na leitura das políticas e ações desenvolvidas no espaço agrário, que se constitui no território amazônico a partir dos diferentes usos da terra, como é o caso da agricultura camponesa, do agronegócio e das já estabelecidas comunidades indígenas e quilombolas da microrregião de Santarém.

Assim, a abordagem do território permite compreender as transformações do uso da terra em Santarém, a partir da emergência da economia globalizada na exportação de commodities, que transforma a Amazônia em uma fronteira do agronegócio, primeiro com a derrubada da floresta pelos madeireiros, depois com a abertura de campos para a pecuária e por fim o reaproveitamento do solo para o cultivo da soja. Castro destaca como ocorre a expansão da pecuária nos limites desta fronteira: 


\begin{abstract}
A Amazônia foi transformada em uma fronteira de commodities. A expansão da pecuária brasileira ocorre na sua fronteira, com frentes peruanas, bolivianas e colombianas. A expansão dos plantios de grãos (arroz, milho e soja) e a exploração de madeira empurram as fronteiras até os seus limites nacionais (CASTRO, 2012, p. 11).
\end{abstract}

É a partir desta expansão da pecuária que as fronteiras amazônicas vêm transformando o território santareno, notadamente pela ocupação da soja em áreas de pastagem, o que acaba por expandir cada vez mais a pecuária para novas áreas. No entanto, o processo inicia com o corte da madeira, meio mais barato de adquirir a terra e garantir capital financeiro. Somente depois da primeira fase da mercantilização da floresta concluída é que se inicia a conversão das áreas em campos para a pecuária. Devida à baixa produtividade, essas áreas passam a tomar novo valor, agora como especulação fundiária a frente de expansão da soja na Amazônia.

Deste modo, o agronegócio da soja influencia nas transformações do território como parte de um conjunto de ações do processo de produção capitalista na Amazônia, que remodelam o território de acordo com as relações de poder que se confrontam e as relações socioespaciais dos sujeitos com a terra, pois o uso da terra passa a ter novas dinâmicas, sejam estas em conformidade com as demandas capitalistas ou com as (re)esistências das populações que tradicionalmente produzem no território.

\title{
2 LOCALIZAÇÃO E ESPACIALIZAÇÃO DAS NOVAS CONDIÇÕES DE USO DA TERRA NO ESPAÇO RURAL SANTARENO
}

Sem embargo, a introdução de novas estruturas produtivas faz emergir conflitos pelo uso e apropriação da terra, pois a produção de monocultura gera uma série de problemas, principalmente fundiários, antes já estabelecidos nessa região, mas que voltam a fazer parte do cenário a partir da territorialização da soja no município. As comunidades camponesas tornam-se vulneráveis à aquisição do grande volume de terras adquiridas pelos sojicultores nas imediações das comunidades, chegando a diminuir sua população devidoà venda de terras dentro das comunidades para esses produtores, causando o êxodo rural ou a ocupação de novas áreas camponesas. Destaca-se ainda a pressão gerada pela grande quantidade de agrotóxicos utilizados no cultivo de soja, que ocasionam conflitos entre comunitários e sojicultores.

As divergências entres esses atores sociais não é recente no território, pois as diferentes formas de uso da terra sempre foi um vetor de conflito entre os mesmos. As práticas territoriais configuraram as disposições das terras no município, fixando as atividades de grande volume de produção nos eixos rodoviários que cortam o município, como as fazendas de pecuária ao longo da BR-163 (Cuiabá-Santarém) e da PA - 370 (Curuá Una). Neste sentido, é possível perceber na Figura 1, o mapa que mostra a configuração territorial dos usos da terra no ano de 2000, o domínio da pastagem nos eixos rodoviários do município. Esta classificação do uso da terra indica que as pastagens ocupam áreas estratégicas no território viabilizando a exportação do produto através do eixo rodoviário. 
Figura 1: Mapa de uso e ocupação da terra em Santarém em 2000 e 2017

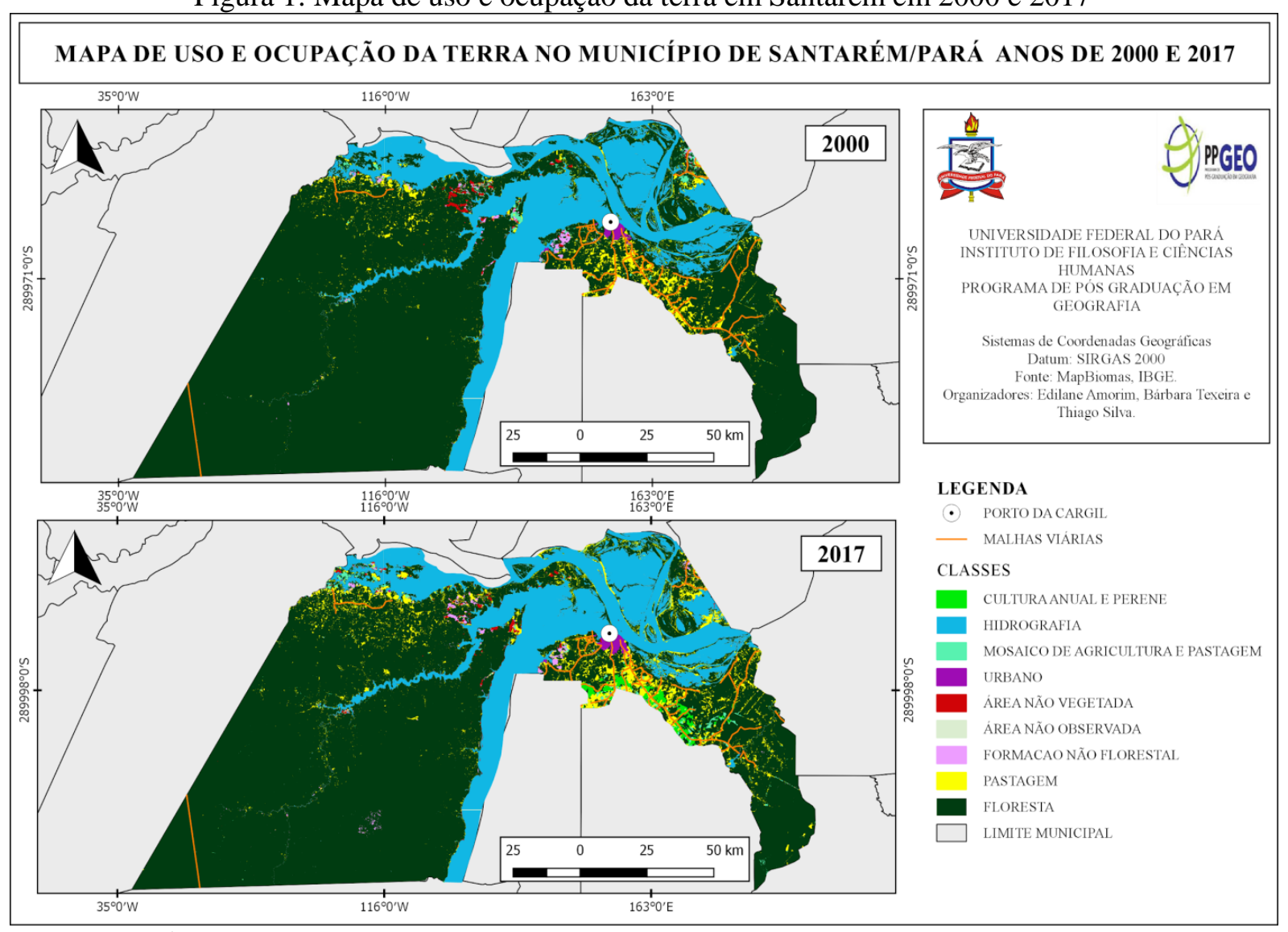

Fonte: MapBiomas, IBGE

Org.: Autores

No segundo mapa da Figura 1, é possível perceber que as áreas que antes eram ocupadas por pastagem passam a dar lugar a cultura anual e perene que compõem um mosaico, composto em maioria pelas culturas do milho, arroz, soja e demais ligadas a cultura de pequenos ciclos, além das perenes. Neste sentido, justifica-se a expansão da soja em áreas já antropizadas pela pecuária ou de agricultura camponesa.

O mapa apresenta o caráter estratégica, ao qual o setor agropecuário vem ultilizando os espaços orientados à produção agrícola e pecuária do municipio, ao passo que essa transformação no uso fica latente pela apropriação, significativas de porções de terras onde se concentram as vias que dão acesso a mancha urbana a ao restantedo território paraense, ligando diretamente aos espaços concentrados de ecoação de matérias primas, produção animal e vegetal, ao qual o município apresenta notoriedade no quadro agropecuário regional. A exemplo, a produção bovina municipal, onde apresenta em 1997 um rebanho bovino de 80.000 mil cabeças de gado, crescendo em 2014 para 132.3000 mil, um aumento de 60,46\% ( FAPESPA, 2016).

Partindo para um recorte mais específico e de forma a adentrar na porção de maior antropização, construímos, a partir dos dados dispostos, uma cartografia de recorte da porção ao sul do município de Santarém, área localizada no raio das principais rodovias da região e próxima 
à malha urbana, onde também se encontra o porto de escoamento da produção de grãos regional (CARGILL).

Dessa forma, a Figura 2 expressa uma composição das classes ligadas às frentes de produção agrícolas compondo o campo do agronegócio da soja e da agricultura camponesa, sendo a cultura anual e perene ligada a soja, milho e culturas de ciclos longos e as incluídas na classe mosaico de agricultura e pastagem, sendo em maiorias as culturas do feijão, milho, mandiocas e demais culturas de pequenos ciclos e pastagem vinculadas à pecuária de pequenas áreas.

O que marca essa porção do território expressa-se no uso antrópico da terra, as produções que impõem uma pressão e, consequentemente, uma transformação territorial. O recorte analítico dos anos de 2006 e 2017, mostra com maior ênfase o avanço de duas classes de forma significativa, dois modos de desenvolvimento se escrevem no tempo, um materializado pela agronegócio tendo a soja como frente de avanço e outro, enraizada na agricultura camponesa, tendo a mandioca e demais culturas de pequeno ciclos como escudo.

Figura 2: Mapa de uso e ocupação da terra em Santarém em 2006 e 2017

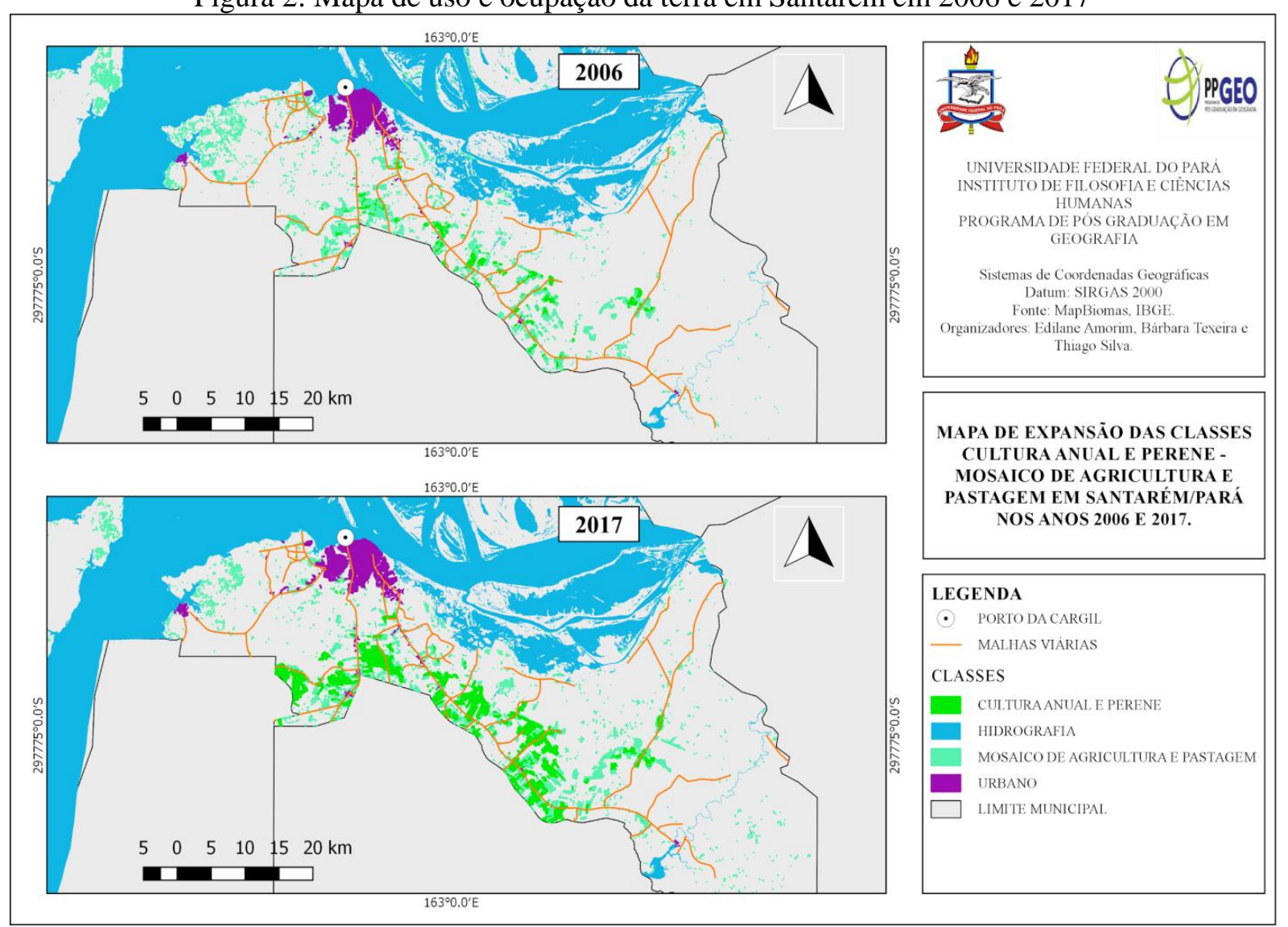

Fonte: MapBiomas, IBGE

Org.: Autores

A cartografia evidencia que há uma disputa silenciosa pelas porções estratégicas para o desenvolvimento, tanto da recente frente capitalista como das produções vinculadas a um caráter mais histórico do camponês. A disputa pelo uso da terra mostra um crescente e significativo avanço da soja nas áreas que, anteriormente, eram ocupadas pela pastagem e pela agricultura camponesa.

Esse avanço do agronegócio, que reverbera em uma alteração no uso da terra, não se inscreve de maneira espontânea ou natural, é pensada de forma externa, mas não sem conhecer as condições locais que permitiram seu sucesso, como já aferido; no primeiro momento vieram 
outras frentes de exploração econômica da terra e da floresta, antecedendo a monocultura da soja, juntamente a esse fator, junta-se a permissões de crédito e de assistência concedidos pelo Estado e estruturas financeiras, além das instituições estatais ligadas ao setor agro técnico.

O caminho dessa leitura é apontar as condições que os locais dispõem para a efetivação do agronegócio, principalmente da soja. A forma como esta cultura vem substituindo outras frentes de produção não é de natureza casual, como nada no território Amazônico se dá pela coincidência; a substituição se encontra em Santos (2014), ao dizer que a produção tem grande ligação com o lugar, uma ligação direta, parte dele condições significativas para sua realização.

Não é só o desejo puro e simples de implantar os desejos e demandas capitalistas no território Amazônico. O próprio local apresenta condições essenciais para sua reprodução de forma àressignificar a dinâmica produtiva, social e econômica do município em questão. Sendo cada lugar, específico para a melhor reprodução e ampliação do modo de produção, a especificidade dos lugares é chave no processo, sendo determinante no papel das formas e no conteúdo produtivo e social. "É esse o próprio princípio da diferenciação entre lugares, produzindo combinações específicas em que as variáveis do todo se encontram de forma particular" (SANTOS, 2012). Os resultados das condições permitidas pelo local estão presentes na figura 2 e gráfico 1.

Gráfico 1: Evolução das classes de cultura anual e perene - mosaico de agricultura e pastagem em 2006 e 2017

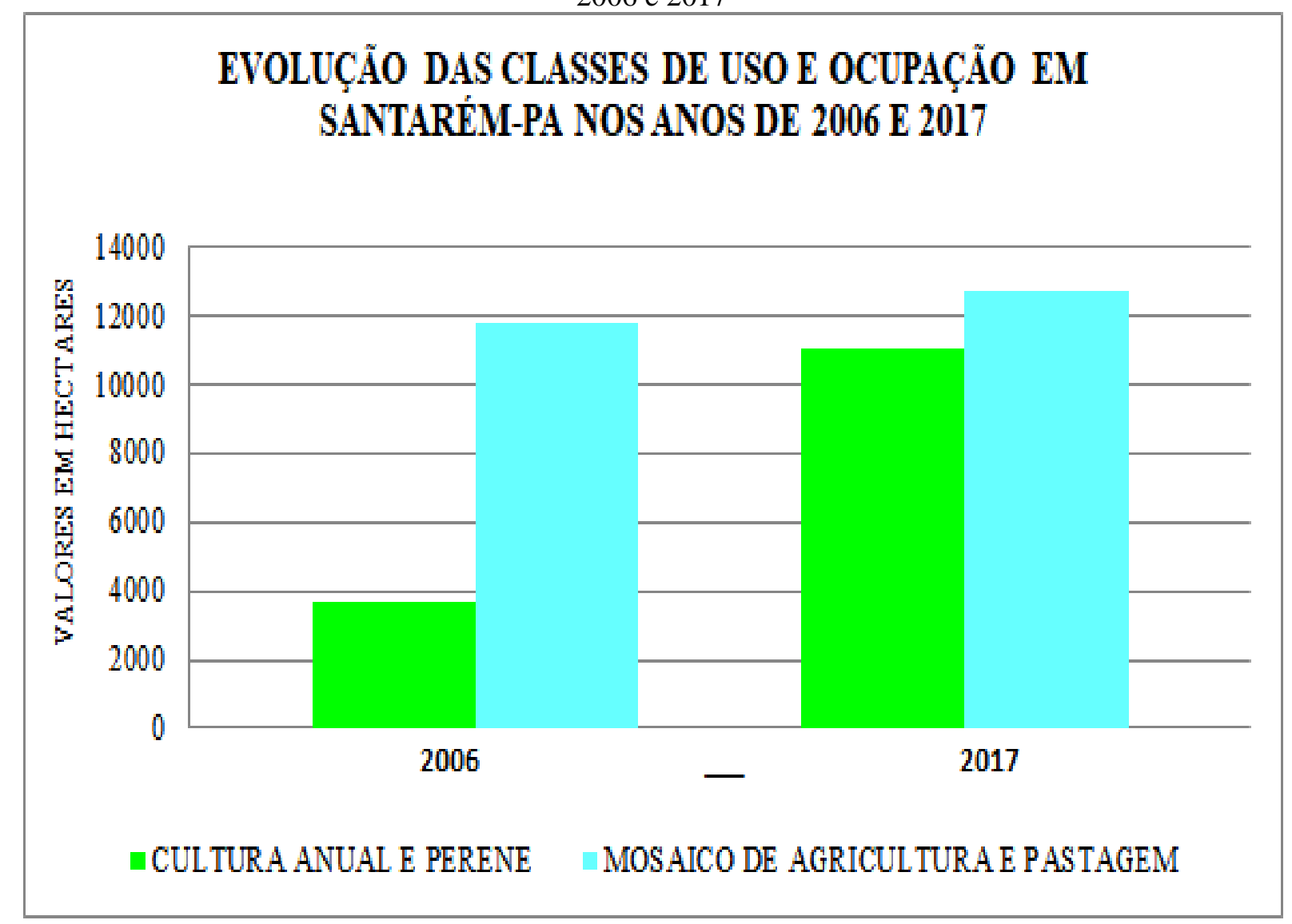

Fonte: IBGE

Org.: Autores

O gráfico expressa a evolução das classes no intervalo de 11 anos, na qual,em 2006, a cultura anual e perene apresenta uma área total de 3.666 hectares e que em 2017 passa a ocupar uma área de 11.076 hectares, expressando um crescimento de 202,13 \%. Esta evolução afere uma forte pressão sobre a dinâmica de uso da terra neste território. Chamamos atenção não somente 
para o crescimento frenético de uma cultura exógena na Amazônia, mas também para a forma como esta se territorializa e especializa-se na região.

A forma estratégica de espacialização da soja em substituição das práticas e dos atores sociais preexistentes vem articulada aos objetos espaciais ideais para sua reprodução e coaduna com o que assevera Santos (2014, p. 61), segundo o qual "Os elementos fixos, fixados em cada lugar, permitem ações que modificam o próprio lugar, fluxos novos ou renovados que recriam as condições ambientais e as condições sociais, e redefinem cada lugar",cujo "sucesso" é viabilizado pela política de estado e pelas condições preexistentes no território, como as estradas e rodovias, as áreas já de uso da agricultura e pastagem, como também sua proximidade para o escoamento, ou seja, a estratégia da soja passa principalmente pelas condições espaciais presentes.

Para elucidação destas estratégias do agronegócio, e de que forma os sistemas de ações interagem com os sistemas de objetos que garantem a fixação e ampliação da soja em Santarém, recorremos a Santos (2014):

Sistemas de objetos e sistemas de ações interagem. De um lado, os sistemas de objetos condicionam a forma como se dão as ações e, de outro, o sistema de ações leva à criação de objetos novos ou se realiza sobre objetos preexistentes. É assim que o espaço encontra a sua dinâmica e se transforma (SANTOS, 2014, p. 62).

Tal quadro fica evidente quando contrapomos os dados do período analisando (20062017), uma vez que a agricultura juntamente com pastagem tem crescido em uma velocidade menor que outras classes, tendo em vista que em 2006esta classe ocupava uma área total expressa em 11.076 hectares, evoluindo para 12.726 hectares em 2017,ou seja, crescendo apenas 14,90\%, alinhado ainda com a substituição e deslocamento desse espaço de produção destinado agora a soja e pastagem e assim, ao passo da ordem externa e conformidades do local, a soja vai redesenhando o território e assumindo os espaços de produção estratégicos à sua reprodução e ampliação. Portanto, o passo necessário a entender o território santareno é entender inicialmente seu uso e ocupação.

\section{CONSIDERAÇÕES FINAIS}

A composição territorial da produção agrícola está marcada por um “dilema”, sendo a movimento silencioso da mudança do espaço destinado à produção, de forma mais objetiva; há nesse território um movimento de substituição/alteração não da produção diretamente, mas das áreas destinadas às culturas. A cartografia da Figura 2 demonstra que, em 2000, havia uma composição agrícola ligada à pastagem e a um mosaico de agricultura camponesa que tem no curso do tempo, contextos e formalidades do velho e do novo, no âmbito da modernização da agricultura. No entanto, essa dinâmica constitui "o modo de produção que expressa-se pela luta e por uma interação entre o novo, que domina, e o velho" (SANTOS, 2012, p. 28).

A Amazônia é marcada por este movimento dicotômico, de um modo de produção novo, possibilitado pelo avanço da técnica, pela velocidade de espacialização e diversos outros fatores que não substitui o velho na totalidade, esse é marcado no passado, possibilitado por outro tempo. O novo vai paulatinamente se desenvolvendo, aperfeiçoando-se em detrimento do velho. Em 
Santarém, o agronegócio da soja representa o novo, viabilizado pelas condições ambientais e pelas contingências criadas por intermédio das políticas públicas que possibilitam a fixação do novo modelo de produção. Ou seja, sua territorialização eespacialização decorre em virtude de um conjunto de fatores que o impulsiona a estabelecer a ordem capitalista no território, sejam naturais e não-naturais, tendo como resultado uma nova configuração territorial erigida sobre a desterritorialização das múltiplas dimensões campesinato preexistente.

\section{REFERÊNCIAS}

BARROS, M. J. B. O avanço do agronegócio da soja sobre terras camponesas em comunidades da rodovia pa 370 em Santarém, Pará. In: XIX ENCONTRO NACIONAL DE GEÓGRAFOS, 2018, João Pessoa. Anais do XIX Encontro Nacional de Geógrafos. João Pessoa: ENG, 2018. V. 1. P. 1-12.

BECKER, B. Geopolítica da Amazônia. Estudos avançados. V.19, n.53, 2005. Disponível: http://www.scielo.br/pdf/ea/v19n53/24081.pdf. Acesso em 25/10/ 2018.

CASTRO, E.Expansão da Fronteira, Megaprojetos de Infraestrutura e Integração Sul-americana. In.: CADERNO CRH, Salvador, v. 25, n. 64, p. 45-61, Jan./Abr, 2012.

CONSELHO DA EUROPA. Carta Européia do Ordenamento do Território. Lisboa: Ministério do Planejamento e da Administração do Território, 1988.

FUNDAÇÃO AMAZONIA DE AMPARO A ESTUDOS E PESQUISAS. Estatísticas Municipais Paraenses: Santarém. / Diretoria de Estatística e de Tecnologia e Gestão da Informação. - Belém, 2016. http://www.fapespa.pa.gov.br. Acesso em: 13/12/ 2018.

NAHUM, J. S.; PAIXÃO JÚNIOR, P. Encontros e desencontros: fronteira, agronegócio da soja e campesinato no Planalto Santareno (PA). Revista NERA (UNESP), v. 25, p. 47-70, 2014.

SANTOS. M. A Natureza do Espaço: Técnica e Tempo, Razão e Emoção. São Paulo: Editora da Universidade de São Paulo, 2014.

SANTOS, M. Da totalidade ao lugar. São Paulo.Editora da Universidade de São Paulo, 2012.

SANTOS, M. Espaço e Método. São Paulo. Editora da Universidade de São Paulo, 2014.

SILVA, C. A. F. Fronteira agrícola capitalista e ordenamento territorial. In: SANTOS, M. BECKER, B. Território, territórios: ensaios sobre o ordenamento. Rio de Janeiro: Lamparina, 2011.

Recebido em: 28/10/2019

Aprovado em: 30/11/2019 